\title{
Using Remotely-Sensed Land Cover and Distribution Modeling to Estimate Tree Species Migration in the Pacific Northwest Region of North America
}

\author{
Nicholas C. Coops ${ }^{1, *}$, Richard H. Waring ${ }^{2, \dagger}$, Andrew Plowright ${ }^{1, \dagger}$, Joanna Lee ${ }^{1,+}$ \\ and Thomas E. Dilts ${ }^{3,+}$ \\ Received: 30 October 2015; Accepted: 8 January 2016; Published: 15 January 2016 \\ Academic Editors: Susan L. Ustin, Parth Sarathi Roy and Prasad S.Thenkabail \\ 1 Department of Forest Resource Management, 2424 Main Mall, University of British Columbia, Vancouver, \\ BC V6T 1Z4, Canada; plowright.andrew@gmail.com (A.P.); leejoannak@gmail.com (J.L.) \\ 2 College of Forestry, Oregon State University, Corvallis, OR 97331, USA; richard.waring@oregonstate.edu \\ 3 Department of Natural Resources and Environmental Science, Mailstop 186, University of Nevada Reno, \\ Reno, NV 89557, USA; tdilts@cabnr.unr.edu \\ * Correspondence: nicholas.coops@ubc.ca; Tel.: +1-604-822-6452; Fax: +1-604-822-9106 \\ + These authors contributed equally to this work.
}

\begin{abstract}
Understanding future tree species migration is challenging due to the unprecedented rate of climate change combined with the presence of human barriers that may limit or impede species movement. Projected changes in climatic conditions outpace migration rates, and more realistic rates of range expansion are needed to make sound environmental policies. In this paper, we develop a modeling approach that takes into account both the geographic changes in the area suitable for the growth and reproduction of tree species, as well as limits imposed geographically on their potential migration using remotely-sensed land cover information. To do so, we combined a physiologically-based decision tree model with a remotely-sensed-derived diffusion-dispersal model to identify the most likely direction of future migration for 15 native tree species in the Pacific Northwest Region of North America, as well as the degree that landscape fragmentation might limit movement. Although projected changes in climate through to 2080 are likely to create favorable environments for range expansion of the 15 tree species by $65 \%$ on average, by limiting the potential movement by previously published migration rates and landscape fragmentation, range expansion will likely be $50 \%-90 \%$ of the potential. The hybrid modeling approach using distribution modeling and remotely-sensed data fills a gap between naïve and more complex approaches to take into account major impediments on the potential migration of native tree species.
\end{abstract}

Keywords: 3PG model; species geographical distribution; climate analysis; decision tree analysis

\section{Introduction}

The distribution of native tree species is largely determined by climate, which needs to be favorable for seed germination, growth and, ultimately, survival of a species [1]. If conditions become less favorable, the resident species must adapt, migrate or face local extinction [2]. For species with large continental distributions, the persistence at the trailing edge (areas from which a species is retreating) of their range is governed by their physiological flexibility and ability to compete successfully with other species, both residents and new migrants [3]. At the front (areas that are seeing the species colonize) of their distribution, a rise in temperature and lengthening of the growing season may facilitate colonization, assuming that the residual flora and fauna are less well adapted to the new conditions [4]. 
The rate at which species migrate has been the subject of many studies globally. Ritchie and MacDonald [5] determined that the spread of white spruce (Picea glauca) in western Canada was far more rapid than in the east following the last retreat of glaciers. It took only about 1000 years for white spruce to spread from south-central Alberta to the MacKenzie Delta $(2000 \mathrm{~km}, 2 \mathrm{~km} /$ year). In contrast, the northeastern migration of the species into the Maritime Provinces was much slower (200-300 m/year). This difference was attributed to prevailing warm winds from the southeast, creating summers favorable for seedling establishment. Similarly, Davis [6] modelled migration rates of beech (Fagus) and hemlock (Tsuga) in Michigan around the Great Lakes during the Holocene. Beech provided an example of a species whose seeds are dispersed by animals, whereas the seeds of hemlock are wind-dispersed. Both species extended their ranges north by about $20-25 \mathrm{~km} /$ century (200-250 m/year). In addition to changes in their horizontal distributions, upslope migration by a species is enhanced by a warming climate. Beckage et al. [7] examined remotely-sensed data (aerial photography and satellite imagery), as well as survey data in Vermont to assess changes in the distribution of a boreal-northern hardwood ecotone between 1964 and 2004. They found that tree basal area had increased just above the upper altitude limits of the original boundary of the ecotone and decreased at the lower altitude limits. The net effect was an overall expansion upslope $\sim 200 \mathrm{~m}$ over the 40-year period.

Climatic distribution models, which may accurately predict the current distributions and abundances of plant species, have different ways of dealing with migration rates: no dispersal, unlimited dispersal, same dispersal rate for all species or more mechanistically complex ways that attempt to account for the density of the seed source [8], landscape fragmentation [9] and dispersal capacity (e.g., Engler et al. [10]). At each level of of increasing complexity there is more uncertainty [11], and as a result, the most common choice is to assume no limit to migration, availability of seed source, or barriers to migration [12]. Yet, migration rates of many species are known to be much less than those associated with recent and projected rates of climate change [13]. As a result, species distribution models exclusively driven by changes in climate are likely to over-predict a species' future distribution [14].

The impact of fragmentation caused by changes in land cover varies among vegetation types. Some species are adapted to fragmentation by becoming highly mobile and, as a result, are less susceptible to human-induced landscape changes. This is particularly true of species that colonize beaches and those that appear immediately following stand-replacement disturbances [12]. Conversely, species that occur at later stages in succession, , and have evolved under more stable conditions, are likely to be highly sensitive to landscape fragmentation. Different thresholds likely exist in the amount of habitat required by different species to migrate successfully. Few studies acknowledge that over time, populations become more spatially dissected as they encounter human-dominated, natural and semi-natural barriers, [12]. Using a cell-based migration simulation model Iverson et al. [15] assessed the potential migration of five tree species from their current northern range limits in the mid-latitudes of the eastern United States. The analysis suggested colonization 10-20 km beyond the current ranges of these species before the end of the 21st century, depending on the appropriateness of the habitat and the species local abundance. Because of the barriers of unsuitable habitat, the advancing front of these species is expected to remain within $10 \mathrm{~km}$ of the current boundaries through the 21st century, although rare long-distance dispersal might establish isolated populations beyond that distance [15].

Thuiller et al. [14] assessed the impact of including land cover data into species distribution models in Europe. They utilized remotely-sensed estimates of land cover and assessed their added utility compared to using climate data alone. They found that at broad spatial scales, land cover patterns were highly correlated with climate, but their statistical impact in the models was reduced, because some land cover patterns were poorly related to climate, such as inland waters and arable land [14]. Importantly, they note that at very broad scales, the relationships between land cover and climate will change, making inclusion of land cover at broad geographic scales (or at different intervals) difficult and likely to introduce error. They suggest that land cover data are most valuable at regional 
scales where direct links between land cover and resource gradients are evident. Honnay et al. [3] examined the shift in the distribution of forest plant species in northern Belgium over the past 40 years. They concluded that $85 \%$ of forest plant species in the study area had very low colonization rates when favorable habitat was spatially isolated or the landscape fragmented. On the other hand, colonization occurred more rapidly where there were few physical barriers to impede migration.

Opdam and Wascher [12] propose three points that merit consideration to address the impact of landscape fragmentation on species migration. They suggest: (i) geo-spatial analysis to locate migration bottlenecks where expansion of a species is likely to be hindered by increased landscape fragmentation or local areas where species are able to migrate into, but not out of, leading to local extinction; (ii) identification of corridors or protected areas that can function as key habitat during migration; and (iii) development of a knowledge base to help planners and managers identify solutions to coping with changing climate within a multifunctional landscape.

In this paper, we incorporate remote sensing data and realistic migration rates into the estimation of future distributions of 15 tree species native to the Pacific Northwest of North America. We intend to address the first two points raised by Opdam and Wascher [12] by locating areas where species' expansion is likely to be hindered by increased landscape fragmentation and provide the first steps towards the identification of corridors that can function as transitional habitat. To do so, we start by assessing how the impact of changing climate might favor or restrict current distributional patterns of the species using decision tree habitat models [16]. We then utilize remotely-sensed land cover information to derive a diffusion-dispersal model to evaluate the capacity of individual species to migrate through fragmented landscapes and ecological barriers, as climatic conditions are projected to change by 2080 .

\section{Methods}

\subsection{Study Area}

Within the Pacific Northwest Region of North America, the distribution of flora in major ecoregions (Figure 1) is largely correlated with spatial variation in temperature and precipitation. The Marine West Coast Forest zone is the most productive of the four subregions with measured maximum values of leaf area index (LAI) generally between 8 and $12 \mathrm{~m}^{2} / \mathrm{m}^{2}$ [17], and it is the zone with the highest percentage of forested land (82\%). Western hemlock (Tsuga heterophylla) and Sitka spruce (Picea sitchensis) are present throughout this maritime-affected zone, with Douglas-fir (Pseudotsuga menziesii), Alaska yellow cedar (Chamaecyparis nootkatensis), western redcedar (Thuja plicata), coast redwood (Sequoia sempervirens) and grand fir (Abies grandis) also represented in some areas.

The Northwest Forested Mountains are the second most productive in the area (55\% forested). Douglas-fir and western hemlock are abundant, with mixtures of Pacific silver fir (Abies amabilis), noble fir (Abies procera) and western larch (Larix occidentalis). At higher elevations and latitudes, lodgepole pine (Pinus contorta), whitebark pine (Pinus albicaulis), mountain hemlock (Tsuga mertensiana), subalpine fir (Abies lasiocarpa) and Engelmann spruce (Picea engelmannii) are also present. Measured maximum LAI varies from 3.0 at some high elevation subalpine forests to 10.0 for the most productive Douglas-fir and hemlock stands $[17,18]$.

On drier sites, ponderosa pine (Pinus ponderosa) and incense cedar (Calocedrus decurrens) are usually present. Ponderosa pine extends its range southward through the Temperate Sierra Ecoregion ( $20 \%$ forested) into the fringe of the North American Desert Ecoregion with further reductions in productivity. In Oregon and Northern California, in the rain shadow of the Cascade and Sierra Nevada Mountains, open pine forests grade into western juniper (Juniperus occidentalis) woodlands and finally to sagebrush steppe $[17,19]$. In these locations, measured LAI ranges between 0.5 and $2.5 \mathrm{~m}^{2} / \mathrm{m}^{2}$. 


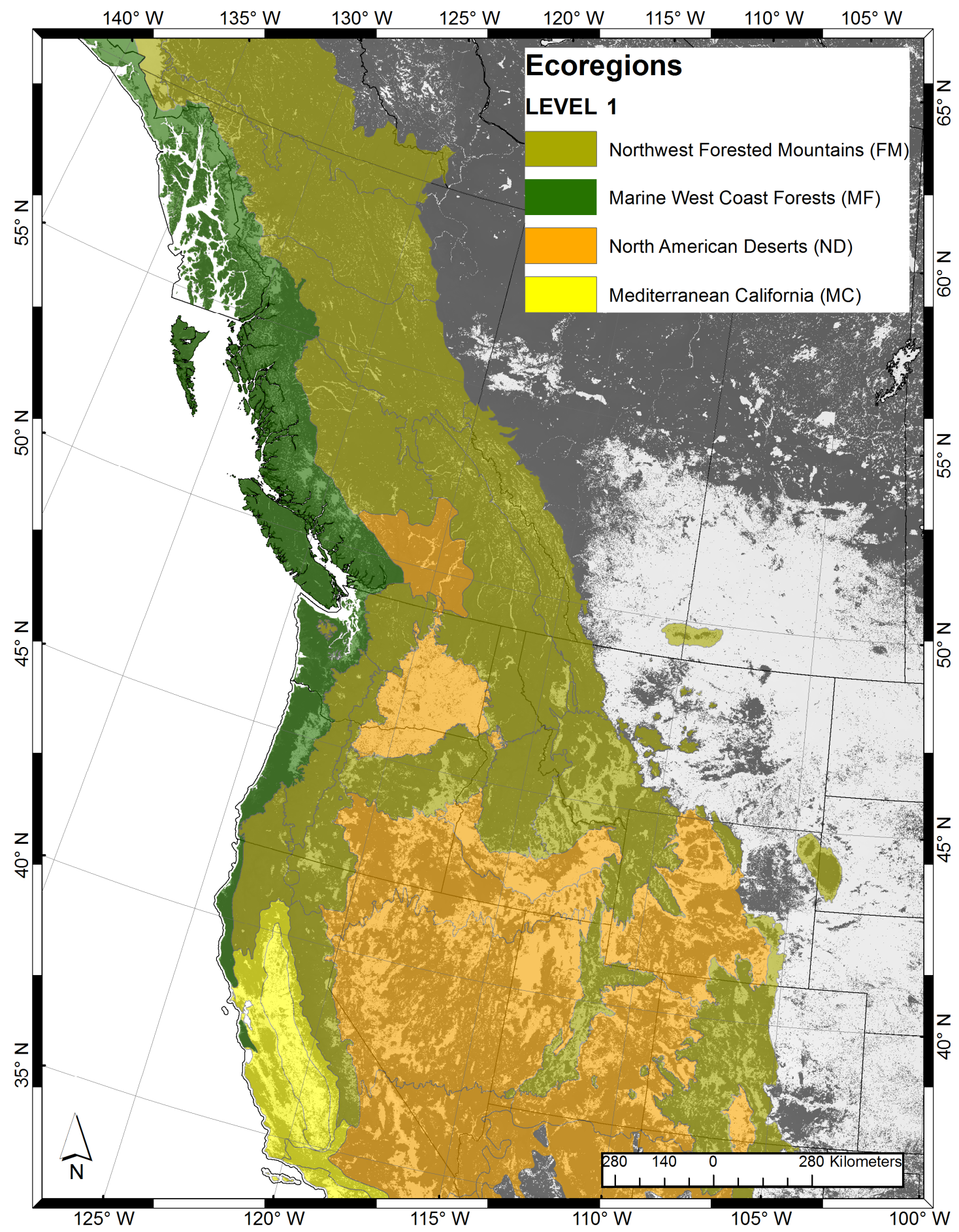

Figure 1. The maritime influence coniferous forests ecoregion (green) is among the most productive in North America. The Northwest Forested Mountain Ecoregion contains a much broader mix of species on less productive sites (olive), whereas the North American Desert Ecoregion includes drought-adapted species, such as ponderosa pine and western juniper.

\subsection{Modeling Approach}

In an earlier paper, we developed a hybrid modeling approach to predict the distribution of 15 native tree species in the Pacific Northwest Region [16]. The benefit of the approach is that it combined the power and simplicity of climatic envelope models with the understanding derived 
from a mechanistic growth model. In addition the approach limits the requirement for detailed physiological knowledge to one widely-distributed species, Douglas-fir. In short, the approach utilizes the 3PG (Physiological Principles Predicting Growth) process-based model, which contains a number of key simplifying assumptions that have emerged from studies conducted over a wide range of forest types, including the use of monthly climate data. Each month, the most limiting climatic variable on photosynthesis is selected, based on conditions that are defined as optimum or completely limited for a particular species [16]. The fraction of production not allocated to roots is partitioned among foliage, stem and branches based on allometric relationships and knowledge of annual leaf turnover [20]. The 3PG model estimates the absorbed photosynthetically-active radiation (APAR) from global solar radiation and LAI, with the utilized APAR portion estimated by reducing APAR by an amount determined from a series of modifiers with values that range between 0 (system "shutdown") and 1 (no constraint) [20]. These modifiers include: (1) averaged day-time vapor pressure deficits (VPD); (2) the frequency of subfreezing conditions; (3) soil drought; and (4) mean daily temperature. A major simplification in 3PG is that it does not require detailed calculation of autotrophic respiration, assuming that it is a fixed fraction $(0.47, \mathrm{SE} \pm 0.04)$ of gross photosynthesis [20]. In our approach, we make the implicit assumption that a species' presence or absence is a function of integrated physiological responses to climatic variation that cause relative differences in the growth rates of competing species [16]. We do not assume that Douglas-fir physiological tolerances exactly match those of other species. Instead, once we characterize geographically the relative importance of seasonal climatic constraints on Douglas-fir photosynthesis, we translate these limitations for other species in reference to how they depart from conditions favorable for Douglas-fir. The different seasonal patterns that emerged to impose limitations on Douglas-fir photosynthesis were incorporated into an automated decision tree analysis to predict the distribution of other tree species across the region [21]. Plot data were acquired from a number of sources, including polygons delineating species occurrence, as well as 22,771 vegetation resource inventory and photo plots from the U.S. and Canada. Accuracy assessments of the models were undertaken in two ways; first, the percentage of plots that a species was correctly assigned as being present or absent, and then combined into a weighted value, proportional to the number of plots associated with each of the two categories. To provide an overall assessment of the error, we utilize the kappa statistic, which is one of the most commonly-used metrics to assess the accuracy of categorical data. While there is debate about the usefulness of the kappa statistic to assess the agreement of classifications that have multiple classes, its use to assess the accuracy of a binary presence/absence species distribution map is well established. While the kappa statistic can vary depending on the number of classes in the classification, when there are only two cases (such as in this case: present or absence), the kappa statistic is a conservative measure of agreement [22]. In addition, we include the degree of positive and negative agreement by species to provide a fair assessment of accuracy when proportions of species can change markedly across the landscape.

The overall accuracy of the models averaged $82 \%$ (Table 1$)$. The most accurate model with respect to modeling its presence was noble fir (92\%) with a kappa value of 0.92 , indicating excellent agreement with the plot observations. In contrast, the poorest prediction of species presence was for lodgepole pine $(68 \%)$ with a kappa of 0.50 , indicating only moderate agreement. The most accurate model with respect to modeling absences was again noble fir (92\%), with the poorest predictions for Engelmann spruce (Picea engelmannii) (68\%). Overall, the presence of a species was predicted with slightly more accuracy than its absence ( $82 \%$ versus $81 \%$, respectively). The overall kappa was 0.74 .

The hybrid modelingapproach offers advantages over existing, more correlative approaches. By starting a climatic analysis with a model that creates a number of biomass pools, we obtain mechanistic insights in regard to the seasonal importance of different variables in different geographic areas. This permits latitudinal variation in the incident radiation and its contribution to photosynthesis and water vapor transfer, as well as the dependence on leaf area index and stomatal conductance at the time of canopy closure (assumed by age 50) to be explicably modelled. We recognize that better agreement between predicted and observed distributions of species could be obtained by increasing 
the numbers of branches and model runs in the decision tree analysis, as demonstrated by Rehfeldt et al. (2006) [23]. Applying these more statistically-sophisticated techniques, however, we believe compromises the ability to define physiological thresholds useful to ecologists and managers.

Table 1. Scientific and common names, as well as the proportion of plots with the presence and absence of the species correctly predicted across the Pacific Northwest region. P indicates Presensce, A; Absence.

\begin{tabular}{|c|c|c|c|c|c|c|c|c|}
\hline Species & Common Name & Code & $\% \mathbf{P}$ & $\% \mathrm{~A}$ & $\begin{array}{c}\text { Presence } \\
\text { Accuracy (\%) }\end{array}$ & $\begin{array}{c}\text { Absence } \\
\text { Accuracy (\%) }\end{array}$ & $\begin{array}{c}\text { Overall } \\
\text { Average }(\%)\end{array}$ & Kappa \\
\hline $\begin{array}{c}\text { Pseudotsuga } \\
\text { menziesii }\end{array}$ & Douglas-fir & DF & 29.2 & 70.8 & 76 & 70 & 73 & 0.584 \\
\hline Thuja plicata & western redcedar & WRC & 13.6 & 86.4 & 80 & 77 & 78 & 0.711 \\
\hline Tsuga heterophylla & western hemlock & WH & 9.3 & 90.8 & 81 & 78 & 80 & 0.740 \\
\hline Tsuga mertensiana & mountain hemlock & MH & 2.1 & 97.9 & 78 & 78 & 78 & 0.711 \\
\hline Pinus contorta & lodgepole pine & LPP & 20.8 & 79.2 & 68 & 72 & 70 & 0.495 \\
\hline Pinus ponderosa & ponderosa pine & PP & 10.5 & 89.5 & 84 & 82 & 83 & 0.785 \\
\hline Picea sitchensis & Sitka spruce & SS & 1.6 & 98.4 & 90 & 88 & 89 & 0.884 \\
\hline Pinus albicaulis & whitebark pine & WP & 2.8 & 97.2 & 84 & 82 & 83 & 0.797 \\
\hline $\begin{array}{l}\text { Chamaecyparis } \\
\text { nootkatensis }\end{array}$ & Alaska yellow cedar & YC & 3.9 & 96.1 & 89 & 91 & 90 & 0.879 \\
\hline Abies procera & noble fir & NF & 0.4 & 99.6 & 92 & 93 & 93 & 0.921 \\
\hline Picea engelmannii & Engelmann spruce & ES & 6.0 & 94 & 78 & 68 & 73 & 0.574 \\
\hline Larix occidentalis & western larch & WL & 2.9 & 97.1 & 81 & 81 & 81 & 0.754 \\
\hline Abies lasiocarpa & subalpine fir & SAF & 10.4 & 89.6 & 76 & 75 & 76 & 0.654 \\
\hline Abies amabilis & Pacific silver fir & PSF & 3.4 & 96.6 & 85 & 83 & 84 & 0.821 \\
\hline Abies grandis & grand fir & GF & 2.6 & 97.4 & 80 & 83 & 82 & 0.805 \\
\hline
\end{tabular}

\subsection{Climate Data}

The models were driven from climatic observations acquired from weather stations distributed throughout the region and interpolated using the model CLIMATE-Western North America (CLIMATE-WNA (www.genetics.forestry.ubc.ca/cfcg/ClimateWNA)), which contains a bilinear interpolation of the PRISM (parameter-elevation regressions on independent slopes model) records, along with adjustments in temperature for mountainous terrain (see [24]). A 90-m digital elevation model (DEM), obtained from the Shuttle Radar Topography Mission (SRTM), was resampled to $1 \mathrm{~km}$ to provide the required elevation data at the same resolution as the climatic data. Most climate models predict that the Pacific Northwest region as a whole will become progressively warmer and perhaps somewhat wetter, with most of the increase in precipitation occurring in winter [25]. The largest changes are predicted to occur to the north, particularly in inland British Columbia and Alberta. In these areas, the frost-free period is expected to increase by at least a month, and periods of extremely warm summer days are likely to become more common. The Canadian Global Climate Model (Version 2), based on the Intergovernmental Panel on Climate Change (IPCC) fourth assessment report with the high emission (A2) scenario, predicts mean annual temperatures to increases $3-5{ }^{\circ} \mathrm{C}$ by 2080-2100 [26].

To assess the impact of landscape fragmentation on the potential migration of species, we first simulated climatic conditions using the Special Report on Emission Scenarios (SRES) climate scenarios published in the (IPCC) Fourth Assessment Report, AR4 [27,28]. Coops et al. [16] describe the suite of models, scenarios and time frames that were simulated. In this paper, we utilized the 2020, 2050 and 2080 A2 scenario that assumes current emissions rates will remain steady until around 2040 and then slowly drop to about half of the current rate by the end of the 21st century. The scenarios were developed from the Canadian Climate Centre's Modeling and Analysis (CCCma) third generation general circulation model (CGCM3), which includes improvements in the treatment of clouds, solar radiation and land surface processes along with a simple ocean mixed-layer model with a thermodynamic sea ice component $[29,30]$. Downscaling of the GCM was undertaken within CLIMATE-WNA (see [24]). 


\subsection{Constraints Imposed by Landscape Fragmentation}

Landscapes dominated by human land use will reduce the mobility of species and cause decreases in the spatial cohesion of landscapes [12]. As a result, the structure of the landscape affects the direction and the density of the dispersing individuals or the seeds between habitat sites [31,32] We assumed that current landscape conditions (land cover) were equivalent to those estimated with the Moderate Resolution Imaging Spectrometer (MODIS) sensor on board the TERRA and AQUA satellites since 2000 and 2002, respectively [33]. MODIS provides a 250-m spatial resolution layer of land cover types, that include those directly induced by humans, as well as those created following natural disturbances. These products were designed specifically for use in regional and global modeling studies [33]. We utilized the land cover classification developed by the International Geosphere-Biosphere Programme Data and Information System (IGBP-DIS) that included 11 classes of natural vegetation, three classes of developed and mosaic lands and three classes of non-vegetated lands. To simplify the analysis, we aggregated the 11 classes into three broad groups: (i) natural vegetation, composed of forests with a mixture of evergreen and deciduous trees, broadleaf and needle-leaf species, and those of mixed composition; (ii) developed and mosaic lands, composed of croplands, urban and built-up properties, and a mosaic of cropland interspersed with natural vegetation; and (iii) areas of non-vegetated classes, composed of water bodies, snow and ice and bare soil or rock.

\subsection{Effect of Land Cover on Migration}

To simulate the migration of the species from current conditions to those envisioned in the 2080s, we did a cost-distance analysis to simulate the suitability of the land cover to support migration for a species. Land cover such as water is obviously completely unable to support terrestrial species and, thus, is a barrier to species movement. In contrast, natural vegetation is assumed to support recruitment and seed production and offers maximum migration capacity. Areas dominated by agriculture and other human-modified land have moderate migration potential depending on grazing, harvesting and mowing [34]. This approach establishes a raster layer defining the cost or difficulty in proceeding through different migration paths, starting with each species' current distribution. This distance-diffusion model applies graph theory, whereby the center of each cell in the raster is considered a node with each node connected to its eight adjacent neighboring cells representing the ordinal directions (N, NE, E, SE, S, SW, W, NW). The analysis starts by evaluating the potential for migration from those cells in which a species is designated as present. With analogy to Ohms' law, the potential for migration in any direction is equivalent to the voltage, and the impedance to movement is proportional to the voltage divided by the resistance that the landscape imposes to movement. A species is predicted to move into an adjacent cell with the lowest accumulated cost, set below a threshold value. The accumulated cost is calculated from the impedance associated with moving through each cell across the landscape. The direction of movement varies based on the composite value per cell, which is assessed as the product of the distance and its impedance to migration. An additional restriction is imposed: a species may migrate to an adjacent cell only if the environmental conditions are predicted to be suitable in each assessed time period.

We weighted the land cover classes (Figure 2) to reflect the relative difficulty that they might represent to migration. The lowest impedance was assigned to natural vegetation, with progressive increases in the value moving through developed and mosaic types to impenetrable landscape barriers. The maximum migration distance (set at $200 \mathrm{~m}$ per year based on the literature cited earlier) we assumed to apply through natural vegetation. The migration rate through developed and mosaic lands was set at $1 / 4$ (4 times the impedance) of that through natural vegetation. To assess the sensitivity of the simulations to the maximum rate of migration and the degree of impedance, we varied the rate from 100-400 m per year, and the impedance of developed and mosaic lands from $1 / 8-1 / 2$ of that for natural vegetation. Simulations were run to evaluate potential movement for each of 15 species, starting from current conditions to 2020, 2020-2050 and finally from 2050-2080 (as shown in Figure 3). 
In each case, migration was permitted into cells where climatic conditions were deemed appropriate for a selected species.

The extent that migration rates might be constrained through the intervening periods to 2080 was evaluated: (1) based on climatic conditions alone; (2) climatic restrictions together with a maximum rate of $200 \mathrm{~m}$ /year; and (3) additional limits imposed by remotely-sensed land cover. We assessed the direction of migration, and predicted the area most likely occupied by each species in 2080 by comparing the area defined by that predicted within each of the $1^{\circ}$ wedges in a circle centered over the current distribution of the species.

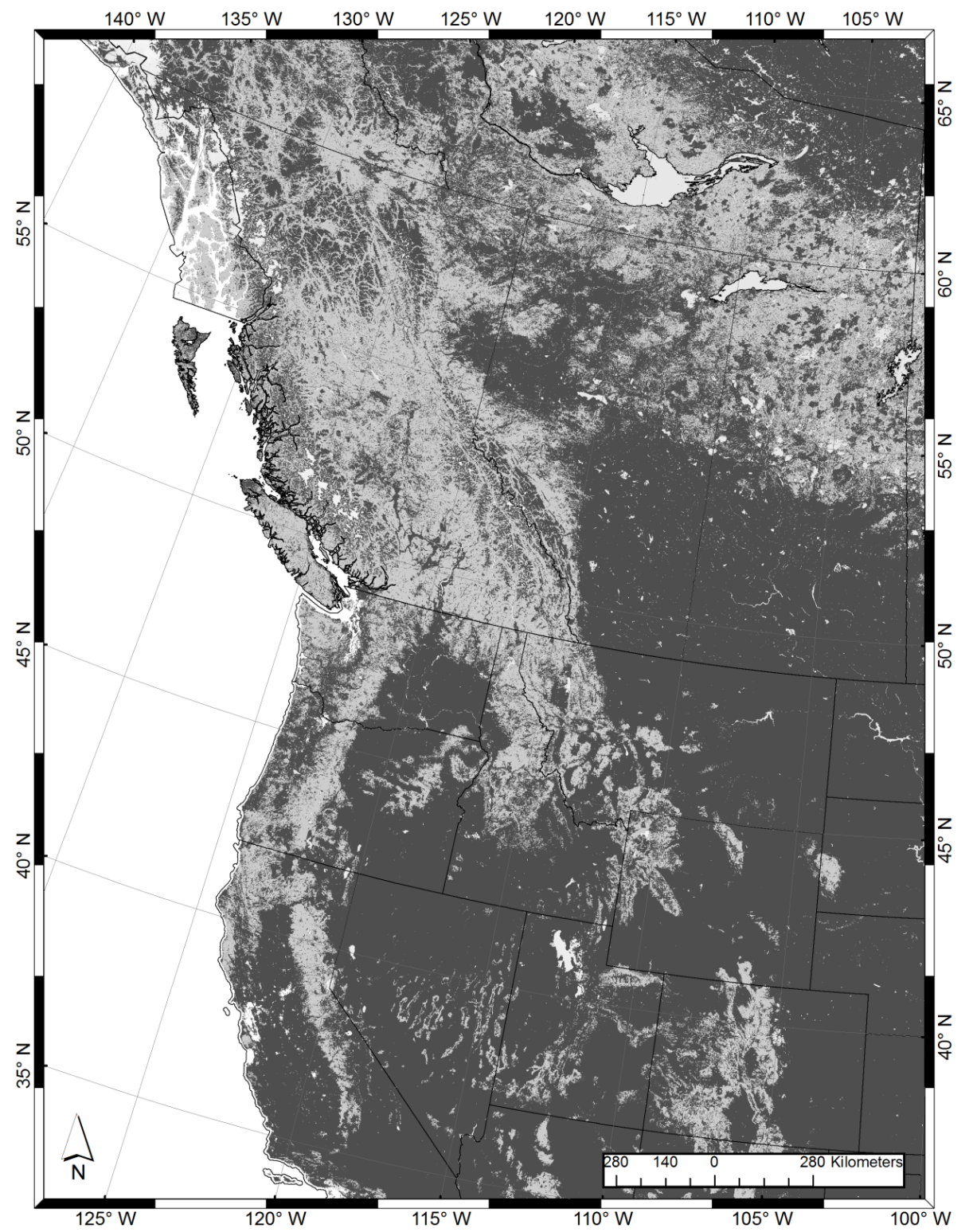

Figure 2. Pacific Northwest Study Area with barriers to migration recognized at three levels of increasing resistance to migration. Land cover classes are weighed to reflect the relative difficulty that they might represent to migration. The lowest impedance was assigned to natural vegetation (dark grey), then developed and mosaic types (black) to impenetrable landscape barrier, such as water (light grey). 


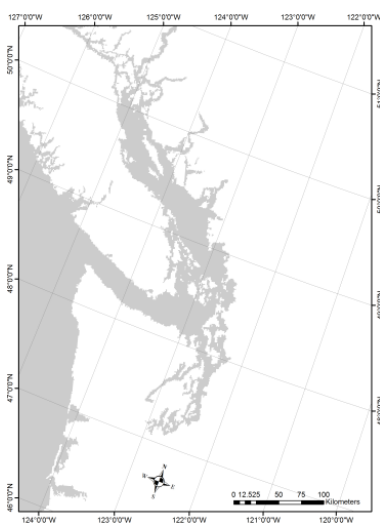

(a)

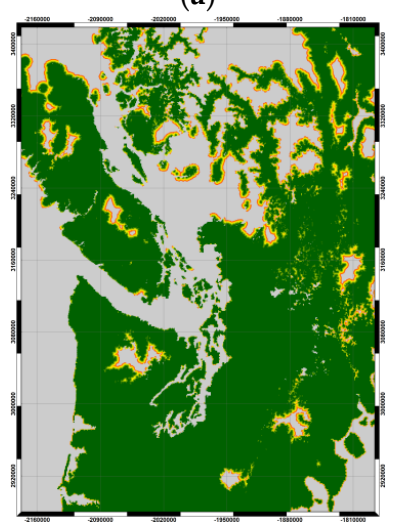

(d)

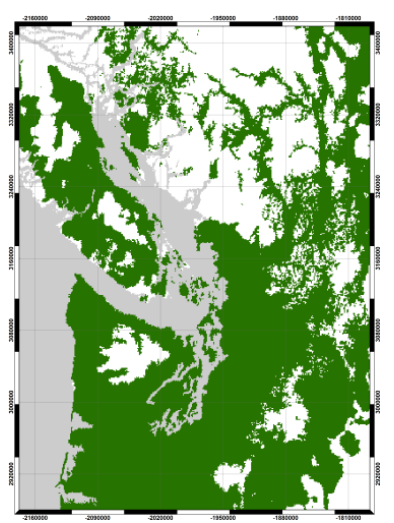

(b)

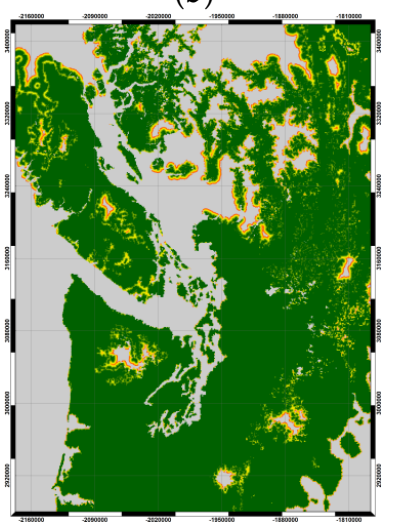

(e)

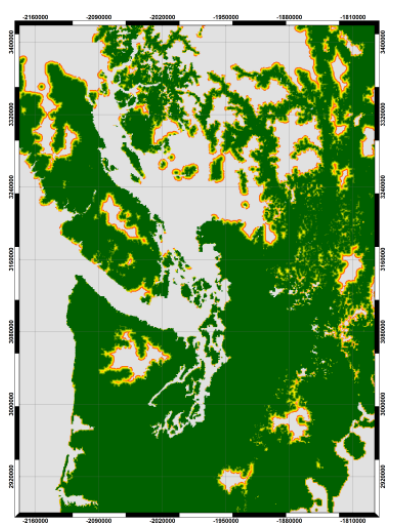

(c)

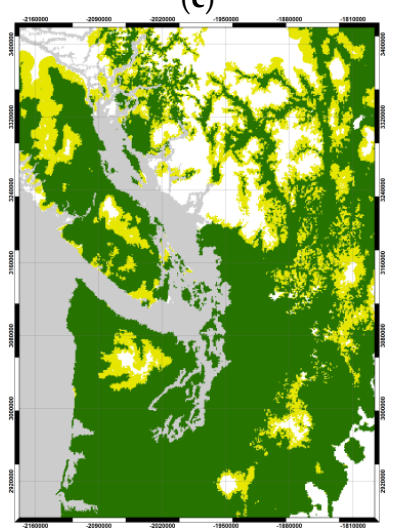

(f)

Figure 3. Depiction of the cost distance and impedance functions. (a) Coordinates and details of the map subset; (b) current distribution of Douglas-fir; (c) with the addition of other landscape barriers, principally representing inhospitable habitat for tree growth; (d) expansion by 2020 limited by unsuitable climate; (e) expansion from 2020-2050 limited by suitable climate; (f) predicted maximum distribution by 2080 constrained by predicted climate and landscape barriers.

\section{Results}

The directional diagrams presented in Figure $4 \mathrm{a}-\mathrm{f}$ illustrate the predicted net changes in distributions of six tree species by 2080, assuming the presence of suitable climate and further impeded by various barriers. The rates of migration are depicted with and without impedance by landscape barriers. In the case of Douglas-fir (Figure 4a), the general direction of migration is principally toward the northwest and southeast. In the northwest, the opportunity for the species to migrate horizontally toward a more favorable climate is observed, whereas in the southeast, migration is more restricted toward higher elevations. There is much less migration predicted for the species toward the less favorable climates in the southwest and the northeast, while the Pacific Ocean halts migration of the coastal populations westward. Without assuming impedance by landscape barriers, there would be, as shown, markedly more migration toward the northwest and, to a lesser extent, also to the southeast. The easterly migration of the species is severely limited by developed and mosaic lands that create fragmented barriers.

In contrast to Douglas-fir, whitebark pine's predicted migration northward is much more restricted and nearly halted by developed and mosaic lands in Northern California and elsewhere in the more arid western states. For western redcedar, we also see a marked constraint on its migration by 2080. The capacity of the species to move in a southerly and easterly direction is small, and even movement toward the northwest is much reduced by 2080, principally due to a highly dissected landscape along the coast of Washington and British Columbia. For ponderosa pine, the pattern of the distribution in 2080 is similar with or without impedance introduced by landscape barriers; however, the species is 
severely limited in its capacity to move eastward, associated with cultural changes in land use and fragmentation. Sitka spruce is the most climatically constrained of the 15 tree species; thus, only small differences are indicated with or without consideration of landscape barriers by 2080. Western hemlock mirrors other coastal species, such as western redcedar, with the direction of migration relatively unchanged, but with a reduced area occupied by 2080 , particularly in the northeastern part of its climatic range.

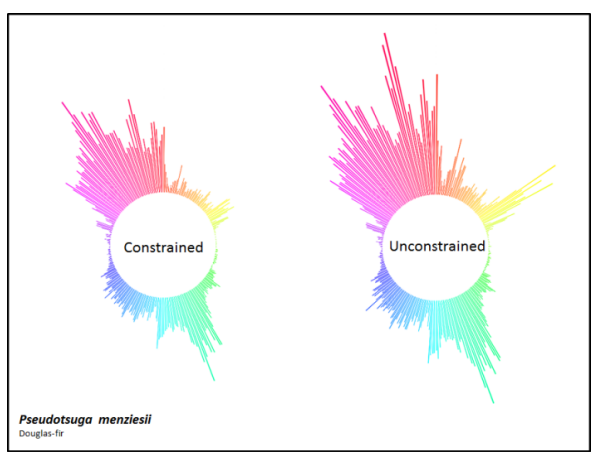

(a)

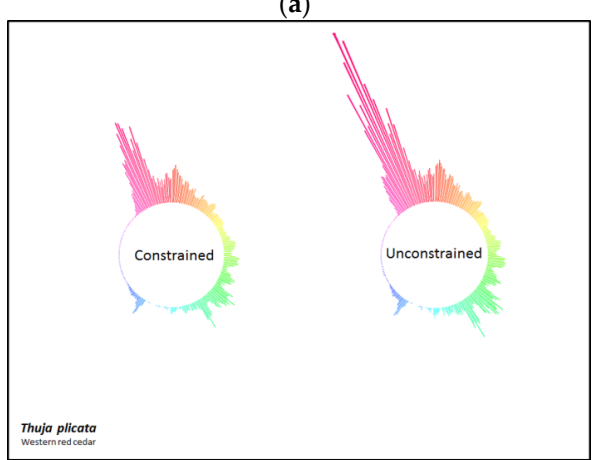

(c)

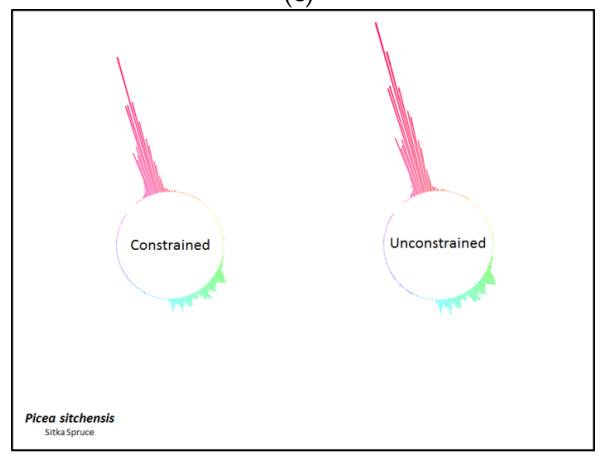

(e)

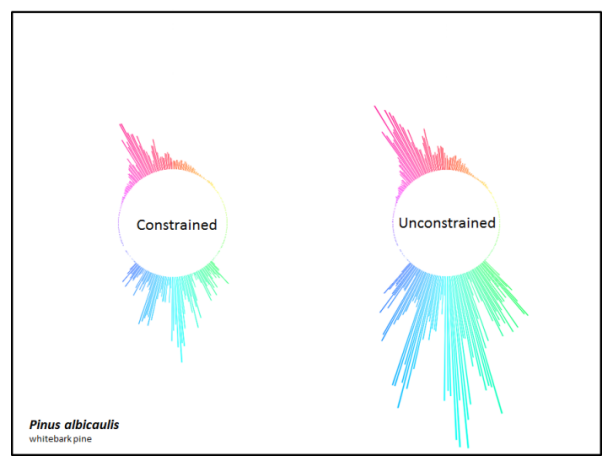

(b)

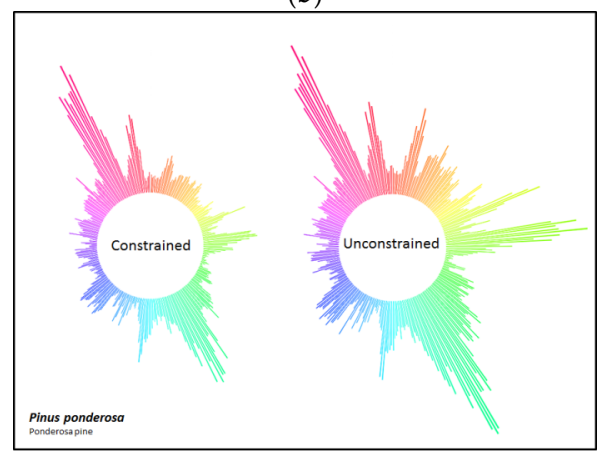

(d)

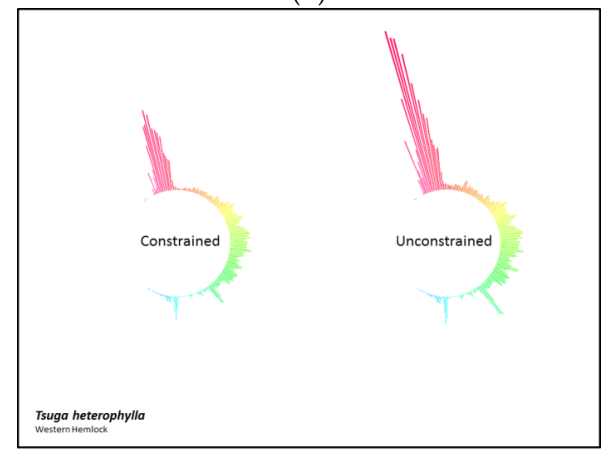

(f)

Figure 4. (a-f) Predicted direction and area (length of the ray) of potential migration by six tree species in response to expected shifts in climatic conditions by 2080. (Left) Migration constrained by realistic maximum rates $(200 \mathrm{~m} / \mathrm{y})$ and landscape barriers; (right) migration constrained by realistic maximum rates $(200 \mathrm{~m} / \mathrm{y})$, but unconstrained by landscape barriers.

Figure 5a-d illustrates the extent that landscape barriers restrict migration rates of four tree species. These figures contrast the current distributions with those imposed by predicted changes in climatic conditions by 2080, as well as the restrictions imposed by favorable or unfavorable migration through different types of land cover. As the distributions demonstrate, the likely future ranges of these species are greatly reduced when realistic migration rates and the barriers imposed by land cover are included. The sensitivity of the simulations for each species to the changing input parameters confirms 
the more climatically restricted the species, the less the choice of parameters there are on the variation of the output. In the case of Sitka spruce, which has significant climatic limitations, increasing the rate of species movement by a factor of two resulted in an area expansion of less than $20 \%$ compared to the base simulations. Increasing the impedance by $1 / 2$, making it more difficult to pass through developed and mosaic lands, also had a relatively minor effect (reducing total area by $15 \%$ of the base simulation). Likewise, for ponderosa pine and western hemlock, both of which are climatically limited, variation of the simulations parameters had variations of less than $30 \%$. For Douglas-fir and whitebark pine, whose distributions are more limited by developed and mosaic lands, the effect was larger. For whitebark pine, doubling the migration rate increased the area of the distribution by $60 \%$, while increasing the impedance reduced the distribution by $33 \%$. In general, varying the migration rate had a slightly larger impact in terms of the area of the distribution than varying the impedance factors.

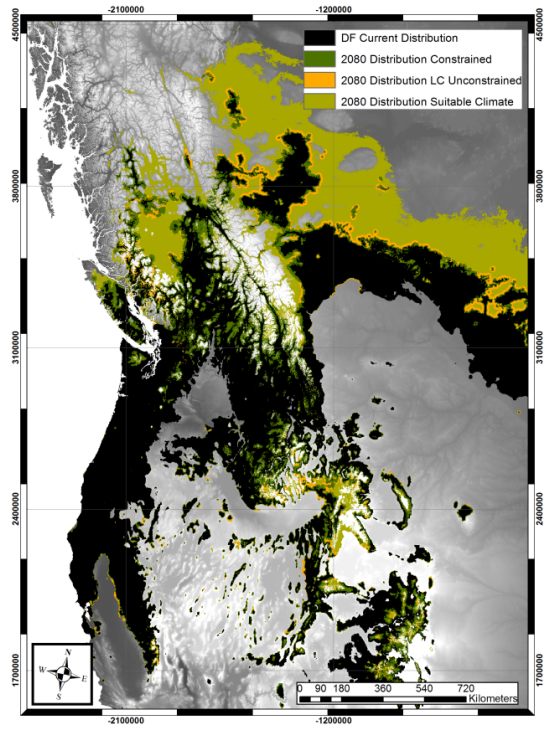

(a)

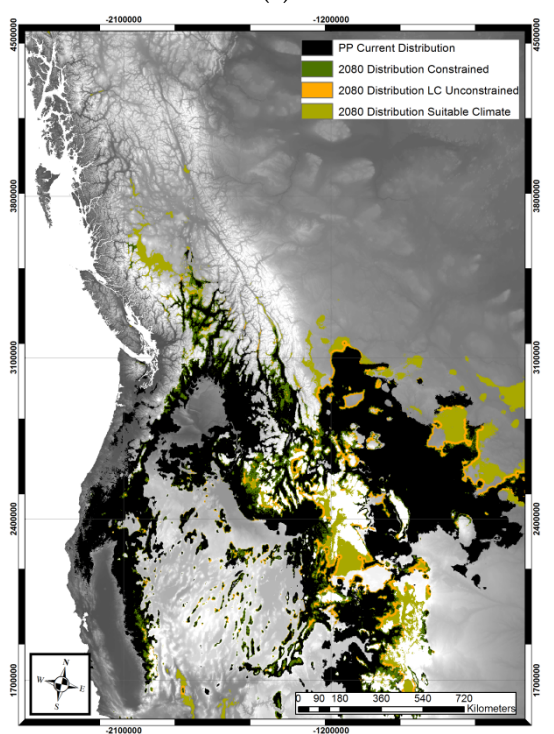

(c)

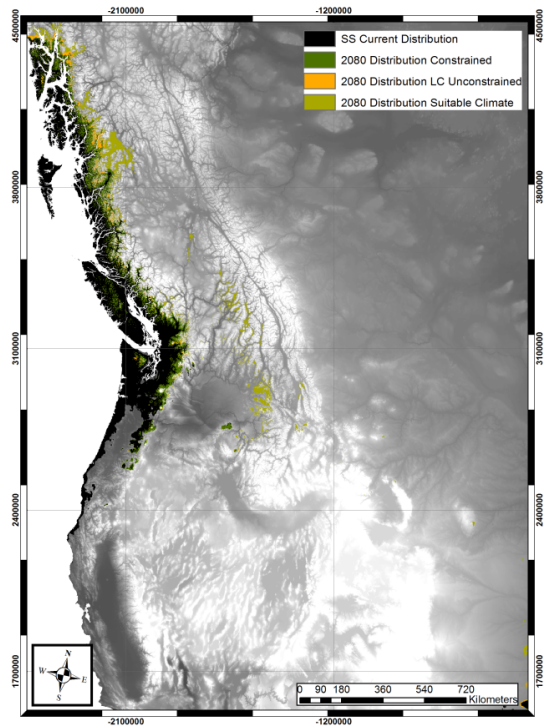

(b)

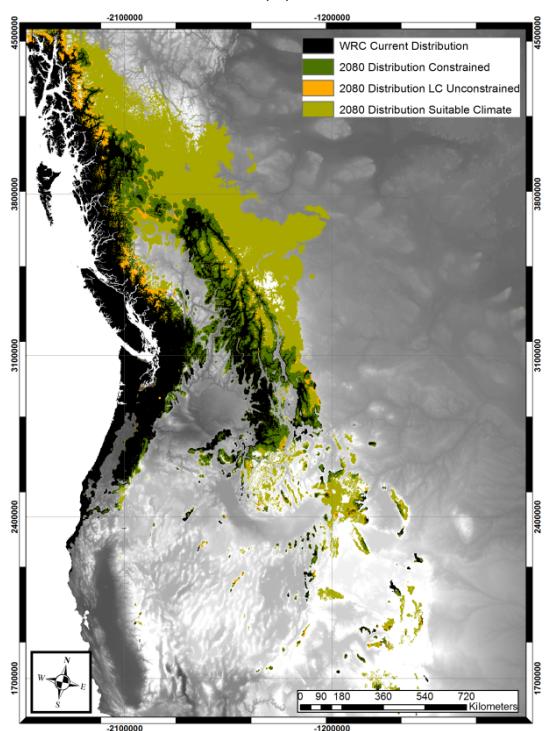

(d)

Figure 5. Predicted distributions of Douglas-fir (DF), Sitka spruce (SS), ponderosa pine (PP) and western redcedar (WWR). For each of the species, the maps depict: (a) current distributions; (b) 2080 distributions with climate and landscape barriers imposed; (c) distributions with a maximum 200-m/y limit constraint (LC) and favorable climatic conditions; and (d) limits imposed by climate alone. 
Figure 6 provides a summary of the differences in the projected ranges of 15 tree species in 2080 as imposed first by climatic conditions only in 2080 and then by the addition of migration rates, then migration rates and landscape barriers. Among the species listed, yellow cedar, western white pine and western hemlock are in a category with a $75 \%-90 \%$ reduction in range caused by landscape barriers. In contrast, Sitka spruce, ponderosa pine and western larch have the smallest restrictions in occupying their climatic potential ranges by 2080. On average, landscape barriers together with limits on natural migration account for between a $50 \%$ and $90 \%$ difference from current distributions of species compared to areas of favorable climate by 2080 .

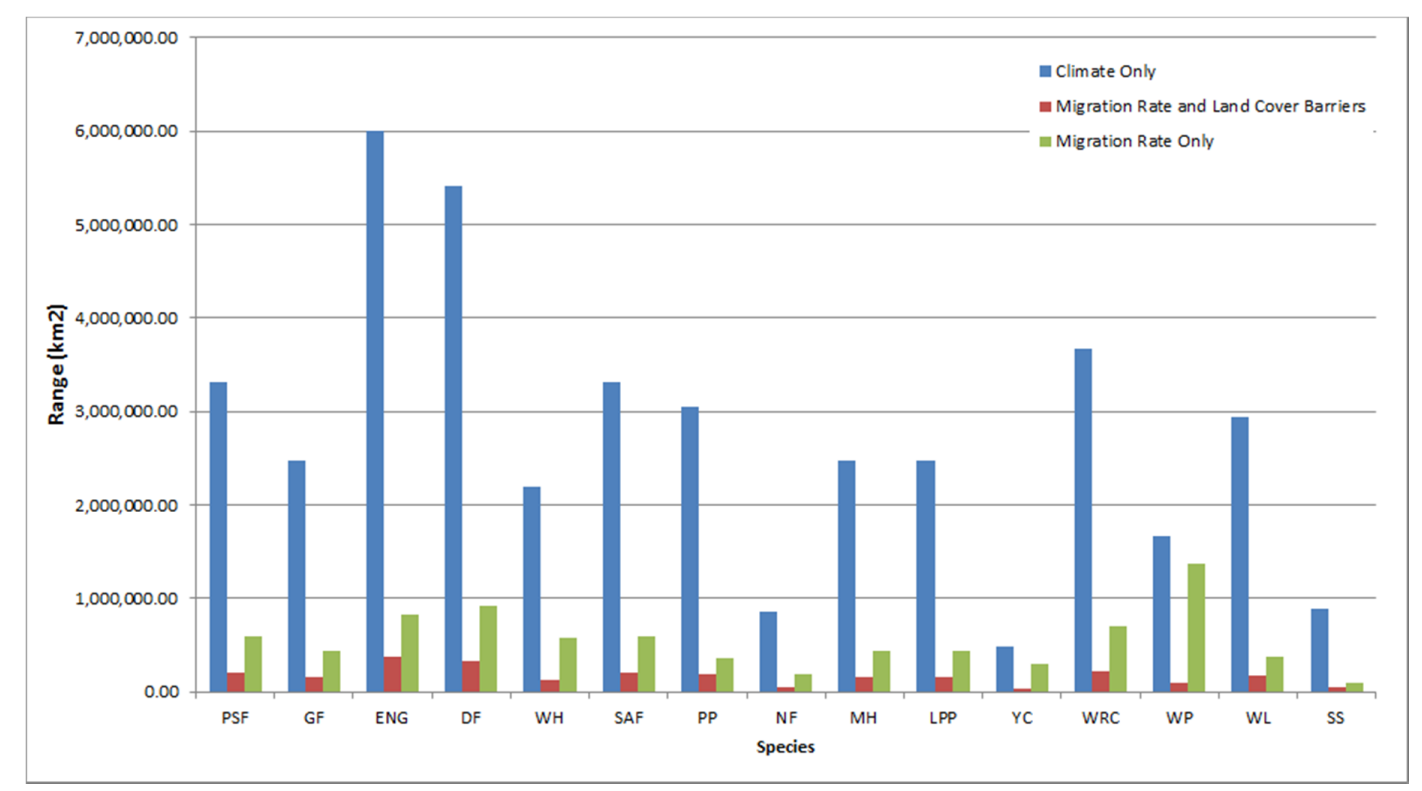

Figure 6. Species ranges $\left(\mathrm{km}^{2}\right.$ and \% difference from current distribution) predicted by 2080 using realistic migration rates (maximum of $200 \mathrm{~km}$ or m/year) and with barriers imposed by land cover and topography. Species abbreviations: Pacific silver fir (PSF), grand fir (GF), Douglas-fir (DF), western hemlock $(\mathrm{WH})$, subalpine fir (SAF), ponderosa pine (PP), noble fir (NF), mountain hemlock $(\mathrm{MH})$, lodgepole pine (LLP), Alaska yellow-cedar (YC), western redcedar (WRC), western white pine (WP), western larch (WL) and Sitka spruce (SS).

\section{Discussion}

The simulations demonstrate that utilizing information on current land use patterns and reasonable rates of species migration under the transition of climatic conditions expected by 2080 are much more spatially constrained than those indicated by using simple climatic envelope models. Although the potential range for expansion will likely significantly increase northerly by 2080 for the tree species investigated using climate-only simulations, the natural rate of expansion is likely much less $(\sim 30 \%)$ when taking into consideration the added difficulty of migration through land cover barriers. The actual distributions of species could contract, depending on the rate that climatic conditions become unsuitable at the trailing edge of their current ranges. The results therefore confirm that the majority of suitable climatic habitat is well beyond the dispersal ability of most species even without considering land use. Once fragmented land use is considered, it serves as an even greater barrier, even in regions, such as Western North America, whose forested areas are considered as relatively intact and wild.

The results demonstrate that in the case of Douglas-fir, the species is unable to reach any of the suitable areas by 2080 in northern British Columbia and Alberta without assistance, thereby severely limiting its capacity to track the velocity of the changing climate. Being unable to quickly and easily move through the interior of British Columbia and Alberta with its human-modified landscapes 
thereby limits its expansion potential when compared to just the distribution based on climate data alone. In the case of Sitka spruce, which predominately occurs along the coast, its range is likely to be climatically limited by 2080, regardless of the land cover through which it must migrate. Ponderosa pine, like Douglas fir, is predicted to have the potential to move eastward by 2080, but with its rate highly restricted by land cover. Of the tree species evaluated, western redcedar is the most hampered by landscape barriers of the tree species evaluated, with the inability to migrate to a future suitable climate further north.

The approach demonstrated here meets a number of needs. It provides a way to identify pinch points and corridors where species can be expected to migrate through, as well as allows the identification of key protected areas that need to be maintained to ensure effective species movement. It also provides a link between climate-based species modelingthat often provides the realized niche of species, with remote sensing technology that provides a landscape perspective of habitat and conditions. Seldom are these two approaches merged, so this technique provides some of the knowledge needed to help managers bring together these two widely-used approaches. Of course, one of the most significant benefits of the integration of remote sensing technology is the repeatable coverage, allowing for consistent and synoptic monitoring, reduced cost (per unit area) and ready access. As a result, barriers to migration corridors can be assessed through time providing a capacity to adapt and assess mitigation options over long time periods.

The benefit of the approach developed here is that it offers a moderate level of complexity, being not as simple as an entirely climatically-driven species distribution modeling approach, or as complex at it might be to account for more barriers to migration. We simplify the problem and make it more tractable by combining our hybrid species modeling approach with remote sensing-estimated landscape maps of barriers that inhibit species migration. We readily acknowledge that some species, such as invasive plant species, often move more rapidly through these areas than through natural vegetation due to anthropogenic influences, disturbance impacts, and so on. Sensitivity analysis to the parameters indicated that the estimated species ranges can vary between $30 \%$ and $60 \%$ of the potential ranges; however, these variations are likely to represent the extremes, as they would involve species moving at more than twice the recorded rate of previous studies. Even if these variations occurred from varying the initial parameters, the simulated ranges would still likely fall within the $50 \%-90 \%$ reduction of the unconstrained ranges found in these simulations. As this approach is further developed, different impedances should be tested and linked to species studies and locations as required; however, estimates, such as the migration rate of species, are highly consistent with rates found for many plant species across the globe [35]. Lastly, the species distribution predictions utilized in the paper reflect a binary presence/absence prediction, which is simplistic in its attempt to assess environmental suitability. More refined species predictions that allow for a more nuanced likelihood of species occurrence could also improve these results.

\section{Conclusions}

We consider the approach presented here is readily adaptable to modification by entering different scenarios in the climate, dispersal mechanisms and impedance values. Having some idea of the most likely route of migration and the barriers imposed is a valuable starting point for developing sound environmental policies for the management, protection and perpetuation of desired communities of species and the ecological services they offer.

Acknowledgments: This study was supported by the National Aeronautics and Space Administration (NASA) Grant NNX11A029G from the program for Biodiversity and Ecological Forecasting to Waring and a Canadian NSERC Discovery grant to Coops. We thank Catherine Ohler, Ryan Frazier and Yuhao Lu for graphical and simulation ideas. We are grateful for excellent comments by the reviewers. More detailed information on the model outputs for each species and their distribution is available at: http://www.databasin.com/.

Author Contributions: Nicholas Coops and Richard Waring conceived the aims and study objectives. All authors developed the methodology and applied the approach. Andrew Plowright, Joanna Lee and Thomas Dilts designed the figures. All authors wrote the manuscript. 
Conflicts of Interest: The authors declare no conflict of interest.

\section{References}

1. Matais, L.; Jump, A.S. Impacts of predicted climate change on recruitment at the geographical limits of Scots pine. J. Exp. Bot. 2013, 65, 299-310.

2. Aitken, S.N.; Yeaman, S.; Holliday, J.A.; Wang, T.; Curtis-McLane, S. Adaptation, mirgation or extirpation: Climate change outcomes for tree populations. Evol. Appl. 2008, 1, 95-111. [CrossRef] [PubMed]

3. Honnay, O.; Veryheyen, K.; Butaye, J.; Jacquemyn, H.; Bossuyt, B.; Hermy, M. Possible effects of habitat fragmentation and climate change on the range of forest plant species. Ecol. Lett. 2012, 5, 525-530. [CrossRef]

4. Hughes, L. Biological consequences of global warming: Is the signal already apparent? Trends Ecol. Evol. 2000, 15, 56-61. [CrossRef]

5. Ritchie, J.C.; MacDonald, G.M. The patterns of post-glacial spread of white spruce. J. Biogeogr. 1986, 13, 537-540. [CrossRef]

6. Davis, M.B. Lags in vegetation response to greenhouse warming. Clim. Change 1989, 15, 75-82. [CrossRef]

7. Beckage, B.; Osborne, B.; Gavin, D.G.; Pucko, C.; Siccama, T.; Perkins, T. A Rapid upward shift of a forest ecotone during 40 years of warming in the Green Mountains of Vermont. PNAS 2008, 105, 4197-4202. [CrossRef] [PubMed]

8. Kubisch, A.; Fronhofer, E.A. Dispersal, evolution and range dynamics-A synthesis. Oikos 2014, 123, 3-4. [CrossRef]

9. Saltré, F.; Duputié, A.; Gaucherel, C.; Chuine, I. How climate, migration ability and habitat fragmentation affect the projected future distribution of European beech. Glob. Change Biol. 2015, 21, 897-910. [CrossRef] [PubMed]

10. Engler, R.; Guisan, A. MigClim: Predicting plant distribution and dispersal in a changing climate. Divers. Distrib. 2009, 15, 590-601. [CrossRef]

11. Thuiller, W.; Albert, C.; Araujo, M.B.; Berry, P.M.; Cabeza, M. Predicting global change impacts on plant species' distributions: Future challenges. Perspect. Plant Ecol. Evol. Syst. 2008, 9, 137-152. [CrossRef]

12. Opdam, P.; Wascher, D. Climate change meets habitat fragmentation: Linking landscape and biogeographical scale levels in research and conservation. Biol. Conserv. 2004, 117, 285-297. [CrossRef]

13. Kramer, K.; Ronce, O.; Robledo-Arnuncio, J.J. Long-distance gene flow and adaption of forest trees to rapid climate change. Ecol. Lett. 2012, 15, 378-392. [CrossRef] [PubMed]

14. Thuiller, W.; Araujo, M.; Lavorel, S. Do we need land cover data to model species distributions in Europe? J. Biogeogr. 2004, 31, 353-361. [CrossRef]

15. Iverson, L.R.; Schwartz, M.W.; Prasad, A.M. How fast and far might tree species migrate in the eastern United States due to climate change? Glob. Ecol. Biogeogr. 2004, 13, 209-219. [CrossRef]

16. Coops, N.C.; Waring, R.H.; Beier, C.; Roy-Jauvin, R.; Wang, T. Modeling coniferous tree species distributions throughout the Pacific Northwest of North America with a generic process-based growth model. Appl. Veg. Sci. 2011, 14, 402-414. [CrossRef]

17. Runyon, J.; Waring, R.H.; Goward, S.N.; Welles, J.W. Environmental limits on net primary production and light-use efficiency across the Oregon transect. Ecol. Appl. 1994, 4, 226-237. [CrossRef]

18. Law, B.E.; Turner, D.; Campbell, J.; Sun, O.J.; van Tuyl, S.; Ritts, W.D.; Cohen, W.B. Disturbance and climate effects on carbon stocks and fluxes across western Oregon USA. Glob. Change Biol. 2004, 10, 1429-1444. [CrossRef]

19. Franklin, J.F.; Dyrness, C.T. Natural vegetation of Oregon and Washington. In Pacific Northwest Forest and Range Experiment Station; General Technical Report; United States Forest Service: Portland, OR, USA, 1973.

20. Landsberg, J.J.; Waring, R.H. A generalised model of forest productivity using simplified concepts of radiation-use efficiency, carbon balance and partitioning. For. Ecol. Manag. 1997, 95, 209-228. [CrossRef]

21. Coops, N.C.; Waring, R.H.; Schroeder, T.A. Combining a generic process- productivity model and a statistical classification method to predict presence and absence of tree species in the Pacific Northwest, USA. Ecol. Model. 2009, 220, 1787-1796. [CrossRef]

22. Uebersax, J.S. Diversity of decision-making models and the measurement of interrater agreement. Psychol. Bull. 1987, 101, 140-146. [CrossRef] 
23. Rehfeldt, G.E.; Crookston, N.L.; Warwell, M.V.; Evans, J.S. Empirical analysis of plant-climate relationships for the western United States. Int. J. Plant Sci. 2006, 167, 1123-1150. [CrossRef]

24. Hamann, A.; Wang, T. Potential effects of climate change on ecosystem and tree species distribution in British Columbia. Ecology 2006, 87, 2773-2786. [CrossRef]

25. Mote, P.W.; Parson, E.A.; Hamlet, A.F.; Ideker, K.N.; Keeton, W.S.; Lettenmaier, D.P.; Mantua, N.J.; Miles, E.L.; Peterson, D.W.; Peterson, D.L.; et al. Preparing for climate change: The water, salmon and forests of the Pacific Northwest. Clim. Chang. 2003, 61, 45-88. [CrossRef]

26. Spittlehouse, D.L. Climate Change, Impacts, and Adaptation Scenarios: Climate Change and Forest and Range Management in British Columbia; Technical Report; B.C. Ministry of Forests \& Range, Research Branch: Victoria, BC, Canada, 2008; p. 38.

27. Nakićenović, N.; Swart, R. Special Report on Emissions Scenarios; A Special Report of Working Group III of the Intergovernmental Panel on Climate Change; Cambridge University Press: Cambridge, UK, 2000; p. 599.

28. IPCC. Summary for policymakers. In Climate Change 2007: The Physical Science Basis. Contribution of Working Group I to the Fourth Assessment Report of the Intergovernmental Panel on Climate Change; Solomon, S.D., Qin, M., Manning, Z., Chen, M., Marquis, K.B., Averytm, M., Tignor, H., Miller, L., Eds.; Cambridge University Press: Cambridge, UK; New York, NY, USA; p. 996.

29. McFarlane, N.A.; Scinocca, J.F.; Lazare, M.; Harvey, R.; Verseghy, D.; Li, J. The CCCma Third Generation Atmospheric General Circulation Model; Internal Report; Canadian Centre for Climate Modelling and Analysis: Victoria, BC, Canada, 2005; p. 25.

30. Scinocca, J.F.; McFarlane, N.A.; Lazare, M.; Li, J.; Plummer, D. The CCCma third generation AGCM and its extension into the middle atmosphere. Atmos Chem. Phys. 2008, 8, 7883-7930. [CrossRef]

31. Schumaker, N.H. Using landscape indices to predict habitat connectivity. Ecology 1996, 77, 1210-1225. [CrossRef]

32. Vos, C.C.; Baveco, H.; Grashof-Bokdam, C.J. Corridors and species dispersal. In Applying Landscape Ecology in Biological Conservation; Springer: New York, NY, USA, 2002; pp. 84-104.

33. Friedl, M.A.; McIver, D.K.; Hodges, J.C.F.; Zhang, X.Y.; Muchoney, D.; Strahler, A.H.; Woodcock, C.E.; Gopal, S.; Schneider, A.; Cooper, A.; et al. Global land cover mapping from MODIS: Algorithms and early results. Remote Sens. Environ. 2002, 83, 287-302. [CrossRef]

34. Boulangeat, I.; Georges, D.; Dentant, C.; Bonet, R.; van Es, J.; Abdulhak, S.; Zimmermann, N.E.; Thuiller, W. Anticipating the spatio-temporal response of plant diversity and vegetation structure to climate and land use change in a protected area. Ecography 2014, 37, 1230-1239. [CrossRef] [PubMed]

35. Meier, E.S.; Lischke, H.; Schmatz, D.R.; Zimmermann, N.E. Climate, competition, and connectivity affect future migration and ranges of European trees. Glob. Ecol. Biogeogr. 2012, 21, 164-178. [CrossRef]

(C) 2016 by the authors; licensee MDPI, Basel, Switzerland. This article is an open access article distributed under the terms and conditions of the Creative Commons by Attribution (CC-BY) license (http://creativecommons.org/licenses/by/4.0/). 